\title{
Influence of the Photoluminescent Pigments' Particle Size Distribution on the After Glow Duration
}

\author{
A. Tunali And N.T. Selli \\ Eczacibasi Building Product Co., VitrA Innovation Center, Bozuyuk/Bilecik, Turkey
}

\begin{abstract}
Novel inorganic luminescent materials have provided improvements in lighting, display, and optical devices. They are generally used for decorative applications, safety signs, and tolls. The characteristics of the photoluminescent pigments depend on both physical and chemical characteristics. In this study, particle size distribution effects on the after-glow time of the bluish-green and yellowish-green pigments were investigated. Milling times of the pigments were chosen as $30 \mathrm{~min}, 60 \mathrm{~min}$ and $90 \mathrm{~min}$ and they were applied on the wall tile surfaces with a constant ratio. Depending on the milling time, after-glow property of the pigments were compared by using photometer equipment. Correlations between pigments particle size distribution and after-glow time of the pigments were also discussed in this presentation.
\end{abstract}

DOI: $10.12693 /$ APhysPolA.125.513

PACS: $78.55 . \mathrm{Hx}$

\section{Introduction}

The scientific research, synthesis, and development of novel phosphors started more than 100 years ago with the preparation of zinc sulfide type phosphors, which eventually saw use in television tubes [1]. From the late 19th century to 20th century, active and extensive research had been done on the development and description of the concept of host lattices doped with luminescence activators, and alkaline-earth chalcogenides. In addition to the transition metals some rare-earth ions were also used as activators. Development of spectroscopic techniques and luminescence mechanistic models lead to a variety of technically important practical applications for phosphors such as light sources, display devices, detector systems and many others [2-4].

In this present study, particle size distribution effects on the after-glow time of the bluish-green and yellowish-green pigments were investigated for decorative application on the wall tile surfaces.

\section{Experimental procedure}

In this study, $\mathrm{SrAl}_{2} \mathrm{O}_{4}$ phosphorescent pigments with long-term phosphorescence which were bluish-green denoted as $\mathrm{S}$ and yellowish-green denoted as $\mathrm{Y}$, were used in wall tile vetrosa applications. The chemical analysis of the pigments was shown in Table I.

Pigments were prepared by dry grinding (Retsch PM400) for different times (30, 60, $90 \mathrm{~min})$, particle size and distribution was determined by laser diffraction (Malvern Mastersizer 2000-G). Tests on wall tile vetrosa applications were carried out for pigments derived in the last stage of the study. Phosphorescent pigment added vetrosa frit was applied on glazed wall tile surfaces. To that end, phosphorescent pigments in different proportions were added to different vetrosa frit compounds and tests were performed to determine the optimal firing temperature and duration. Furthermore, the effect of grain
TABLE I

Chemical compositions of the phosphorescent pigments.

\begin{tabular}{c|c|c}
\hline \hline Compositions & $\mathrm{S}$ & $\mathrm{Y}$ \\
\hline $\mathrm{SiO}_{2}$ & 32.55 & 0.11 \\
$\mathrm{SrO}$ & 53.29 & 46.29 \\
$\mathrm{Eu}_{2} \mathrm{O}_{3}$ & 0.38 & 0.49 \\
$\mathrm{Fe}_{2} \mathrm{O}_{3}$ & 0.20 & 0.20 \\
$\mathrm{MgO}$ & 11.70 & - \\
$\mathrm{Dy}{ }_{2} \mathrm{O}_{3}$ & 0.64 & 0.84 \\
$\mathrm{CaO}$ & - & 0.08
\end{tabular}

size of phosphorescent pigments on the afterglow property examined by using Photometer (LS-100, Konica, Minolta). After glow property was determined considering the glowness of the sample in darkness versus time.

\section{Results and discussion}

For examining the effect of the grain size distribution of the phosphorescent pigment on the after glow property, firstly pigments were grinded with different time. The results of the grain size distributions were presented in Table II.

As the milling time increases, grain size decreases. For $\mathrm{S}$ pigment $D(0.9)$ values are: $46.2 \mu \mathrm{m}$ after $30 \mathrm{~min}$, $35.9 \mu \mathrm{m}$ after $60 \mathrm{~min}$ and $29.5 \mu \mathrm{m}$ after $90 \mathrm{~min}$. For Y pigment $D(0.9)$ values are: $44.7 \mu \mathrm{m}$ after $30 \mathrm{~min}, 36.3 \mu \mathrm{m}$ after $60 \mathrm{~min}, 33.1 \mu \mathrm{m}$ after $90 \mathrm{~min}$. These results show that dry grinding is effective method for decreasing the pigments particle size. After grinding of the pigments with different time, phosphorescent pigments were added to the vetrosa frit composition at the same proportions and then they were applied on the wall tile surfaces and fired.

Then, after glow property of the S-pigments and Y-pigments versus grinding time was compared in Fig. 1 
TABLE II

Particle size distribution of the pigments depend on milling time.

\begin{tabular}{c|c|c|c|c}
\hline \hline Pigments & $\begin{array}{c}\text { Milling } \\
\text { time }\end{array}$ & $\begin{array}{c}D(0.1) \\
{[\mu \mathrm{m}]}\end{array}$ & $\begin{array}{c}D(0.5) \\
{[\mu \mathrm{m}]}\end{array}$ & $\begin{array}{c}D(0.9) \\
{[\mu \mathrm{m}]}\end{array}$ \\
\hline $\mathrm{S}$ & $30 \mathrm{~min}$ & 3.1 & 18.8 & 46.2 \\
$\mathrm{~S}$ & $60 \mathrm{~min}$ & 2.4 & 13 & 35.9 \\
$\mathrm{~S}$ & $90 \mathrm{~min}$ & 1.8 & 9.7 & 29.5 \\
$\mathrm{Y}$ & $30 \mathrm{~min}$ & 2.9 & 15.8 & 44.7 \\
$\mathrm{Y}$ & $60 \mathrm{~min}$ & 2.7 & 12.4 & 36.3 \\
$\mathrm{Y}$ & $90 \mathrm{~min}$ & 2.6 & 10.9 & 33.1
\end{tabular}

and Fig. 2. Luminescence intensity of S-pigment (milled for $30 \mathrm{~min}$ ) was $250 \mathrm{mcd}$ after $1 \mathrm{~min}, 15 \mathrm{mcd}$ after $30 \mathrm{~min}$ and $10 \mathrm{mcd}$ after $60 \mathrm{~min}$. Increase of the milling time to $60 \mathrm{~min}$, results in $260 \mathrm{mcd}$ after $1 \mathrm{~min}, 10 \mathrm{mcd}$ after $30 \mathrm{~min}, 10 \mathrm{mcd}$ after $60 \mathrm{~min}$. Finally $90 \mathrm{~min}$ milling results in $240 \mathrm{mcd}$ after $1 \mathrm{~min}, 20 \mathrm{mcd}$ after $30 \mathrm{~min}$ and 10 mcd after $60 \mathrm{~min}$ in the darkness (Fig. 1).

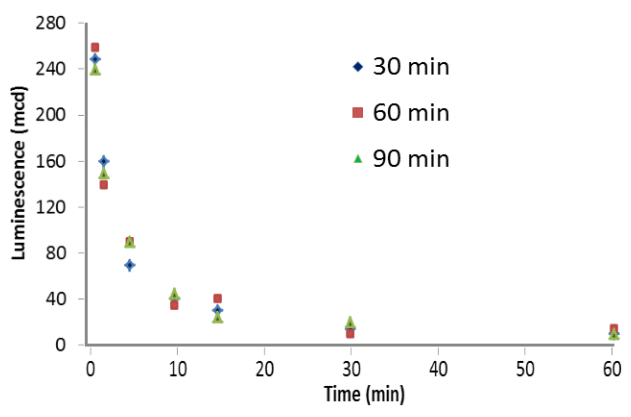

Fig. 1. After glow property of the S-pigments versus grinding time.

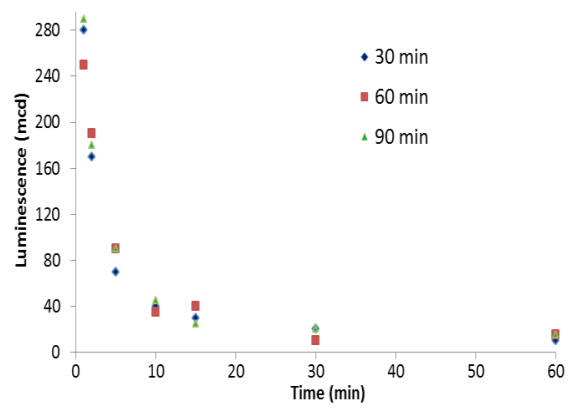

Fig. 2. After glow property of the Y-pigments versus grinding time.
Luminescence intensity of $\mathrm{Y}$ pigments (milled for $30 \mathrm{~min}$ ) was $280 \mathrm{mcd}$ after $1 \mathrm{~min}, 20 \mathrm{mcd}$ after $30 \mathrm{~min}$, 10 mcd after 60 min without excitation of the sample in the darkness. 60 min milling of the pigments shows that luminescence intensity was $250 \mathrm{mcd}$ after $1 \mathrm{~min}, 15 \mathrm{mcd}$ after $30 \mathrm{~min}$ and $10 \mathrm{mcd}$ after $60 \mathrm{~min}$. Finally, $90 \mathrm{~min}$ milling of the pigment shows $290 \mathrm{mcd}$ after $1 \mathrm{~min}, 20 \mathrm{mcd}$ after $30 \mathrm{~min}$ and $15 \mathrm{mcd}$ after $60 \mathrm{~min}$ without any excitation in the darkness.

\section{Conclusions}

In this study, it has been found that when milling time increases, the grain size of the pigments decreases. Therefore, dry grinding can be successfully applied to the phosphorescent pigments to decrease the grain size. On the other hand, decrease in particle size of the pigments does not cause large differences glow in the dark intensities. However, the particle size reduction of the pigments has allowed to us to study more detailed and thinner decorative patterns on the tile surfaces.

\section{References}

[1] X. Wang, D. Jia, in: Phosphor Handbook, 2nd ed., Eds. W.M. Yen, S. Shionoya, H. Yamamoto, CRC Press, Boca Raton (FL) 2007, p. 820.

[2] A. Zukauskas, M.S. Shur, R. Gaska, Introduction to Solid-State Lighting, Wiley, New York 2002.

[3] R.C. Ropp, Luminescence and Solid State, 2nd ed., Elsevier, Netherlands 2004.

[4] S. Kaya Yesilay, B. Karasu, Ceram. Techn. 34, 94 (2012). 